\title{
Silylboronate-Mediated
}

\section{Defluorosilylation of Aryl Fluorides with or without Ni-Catalyst}

\author{
Jun Zhou ${ }^{1}$, Zhengyu Zhao ${ }^{1}$ and Norio Shibata, ${ }^{1,2 *}$ \\ ${ }^{1}$ Department of Nanopharmaceutical Sciences, Nagoya Institute of Technology, Nagoya, Japan, ${ }^{2}$ Institute of Advanced Fluorine- \\ Containing Materials, Zhejiang Normal University, Jinhua, China
}

The defluorosilylation of aryl fluorides to access aryl silanes was achieved under transitionmetal-free conditions via an inert C-F bond activation. The defluorosilylation, mediated by silylboronates and KOtBu, proceeded smoothly at room temperature to afford various aryl silanes in good yields. Although a comparative experiment indicated that $\mathrm{Ni}$ catalyst facilitated this transformation more efficiently, the transition-metal-free protocol is advantageous from a green chemistry perspective.

Keywords: defluorosilylation, transition-metal-free catalysis, C-F bond activation, silylboronate, nickel

\section{INTRODUCTION}

\section{OPEN ACCESS}

Edited by:

Iwao Ojima,

Stony Brook University, United States

Reviewed by:

Ming-Yu Ngai,

Stony Brook University, United States

Santos Fustero,

University of Valencia, Spain

*Correspondence:

Norio Shibata

nozshiba@nitech.ac.jp

Specialty section:

This article was submitted to

Organic Chemistry,

a section of the journal

Frontiers in Chemistry

Received: 06 September 2021 Accepted: 04 October 2021

Published: 25 October 2021

Citation:

Zhou J, Zhao Z and Shibata N (2021)

Silylboronate-Mediated

Defluorosilylation of Aryl Fluorides with

or without Ni-Catalyst.

Front. Chem. 9:771473.

doi: 10.3389/fchem.2021.771473
Organofluorine compounds have been critical over the past few decades in pharmaceutical (Inoue et al., 2020), agrochemical (Ogawa et al., 2020), functional materials (Hiyama, 2000; Babudri et al., 2007; Berger et al., 2011; Liu et al., 2017; Liu et al., 2019) and polymer (Améduri et al., 2020) industries. The progress of synthetic technologies exemplified by fluorination (Rozen et al., 1996; Shibata et al., 2007; Furuya et al., 2011; Campbell et al., 2015; Ni et al., 2015; Lee et al., 2016; Zhu et al., 2018) and trifluoromethylation (Ma et al., 2004; Shibata et al., 2008; Shibata et al., 2010; Merino et al., 2014; Liu et al., 2015; Charpentier et al., 2015; Alonso et al., 2015; Xiao et al., 2021) reactions has expressively supported such success and prosperity of organofluorine compounds. One of the most attractive properties of organofluorine compounds is their durability, represented by Teflon ${ }^{\circledR}$, induced by the most vital bond energy of the C-F bond in carbon chemistry (Uneyama et al., 2006; Luo et al., 2007; Amii et al., 2009). However, their robustness has often caused severe persistent environmental toxicity, such as the super-greenhouse effect by fluorocarbons (McCulloch et al., 2003; Velders et al., 2007; Shine and Sturges, 2007; Sovacool et al., 2021) and the bioaccumulation of perfluorooctanoic acid (PFOA) and perfluorooctanesulfonic acid (PFOS) (Vierke et al., 2012; Stanifer et al., 2018; Chen et al., 2019; Li et al., 2020). Given this limitation, recent attention has been focused on the activation and cleavage of remarkably inert C-F bonds of organofluorine molecules, creating a new field of research in fluorine chemistry (Stahl et al., 2013; Ahrens et al., 2015; Shen et al., 2015; Eisenstein et al., 2017; Hamel et al., 2018).

In 2018, we reported a significant achievement on the C-F bond cleavage of aryl fluorides via defluorosilylation using silylboronates $\left(\mathrm{R}_{3} \mathrm{SiBPin}\right)$ in the presence of potassium tert-butoxide $(\mathrm{KO} t \mathrm{Bu})$ and a catalytic amount of $\mathrm{Ni}$. The $\mathrm{C}-\mathrm{F}$ bond cleavage occurred via the five-centered transition state via a $\pi$-nickel complex and a non-classical oxidative pathway (Scheme 1A); (Cui et al., 2018). Notably, we also found that the C-F bond activation did not require an Ni catalyst in the case of alkyl fluorides. The defluorosilylation of alkyl fluorides proceeded smoothly with $\mathrm{R}_{3} \mathrm{SiBPin}$ exclusively in the presence of $\mathrm{KO} t \mathrm{Bu}$. A highly nucleophilic, silyl anionic species directly reacts with alkyl fluorides via a concerted $\mathrm{S}_{\mathrm{N}} 2$ process (Scheme 1B). The defluorosilylation reaction was then successfully reported by several groups (Gao et al., 2019; Liu et al., 2019; Kojima et al., 2019; Mallick 
A Shibata et al., 2018<smiles>Fc1c[R1]ccc1</smiles>

(Ar/Het)

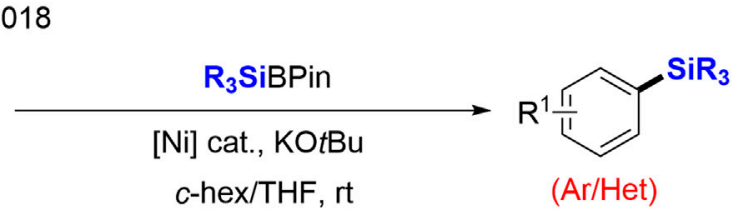

30 examples

B Shibata et al., 2018<smiles>[R]CC([R])F</smiles><smiles>C1CCC(C2CCCC2)CC1</smiles><smiles>[R]CCCF</smiles>

D Uchiyama et al., 2019

E Shibata et al., 2021

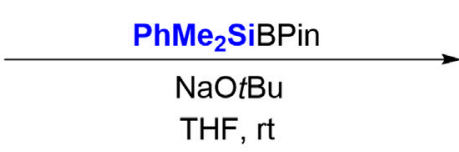

THF, rt

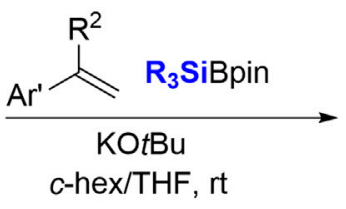

$c$-hex/THF, rt

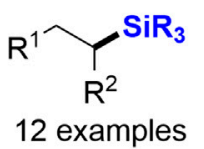

12 examples

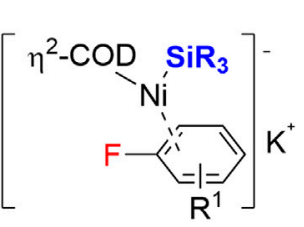<smiles>[R3][SiH](C)N([Te]C(=O)O)c1ccc[R]1F</smiles><smiles>Fc1c[R1]ccc1</smiles><smiles>Fc1c[R1]ccc1</smiles><smiles>Fc1ccccc1</smiles>

(Ar/Het) or Alkyl-F (a) Alkyl-F

C Martin et al., 2019

This work<smiles>[R19][SnH2]c1cc(F)c[14cH][14cH]1</smiles>
(Ar/Het)

1<smiles></smiles>

17 examples

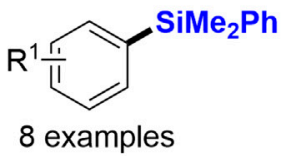

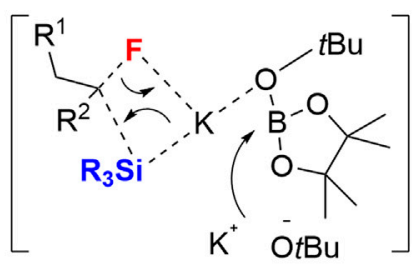

or

9 examples

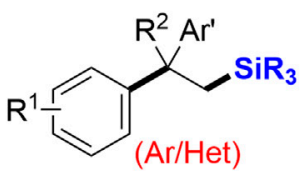

55 examples or<smiles>[R5][SiH2]CC([R])([AlH2])[AlH2]</smiles>

13 examples<smiles>[R1][Bi]c1c[R1]ccc1</smiles>

(Ar/Het) 22 examples

3

SCHEME 1 | Examples of defluorosilylation reactions of organic fluorides with $\mathrm{R}_{3}$ SiBPin.

et al., 2019; Coates et al., 2019; Lim et al., 2020; Sheldon et al., 2020). In 2019, Martin and co-workers reported the lithiumpromoted defluorosilylation of organic fluorides, in which lithium bis(trimethylsilyl)amide (LiHMDS) and dimethyl ether (DME) cooperated well to activate the inert C-F bond (Scheme 1C); (Liu et al., 2019). In the same year, Uchiyama and coworkers also reported a transition-metal-free defluorosilylation of fluoroarenes using $\mathrm{PhMe}_{2} \mathrm{SiBPin}$ and sodium tert-butoxide $(\mathrm{NaO} t \mathrm{Bu})$ (Kojima et al., 2019). In situ generated silyl anion species enabled the direct defluorosilylation of fluoroarenes (Scheme 1D). In 2021, we have continuously reported the catalyst-free carbosilylation of alkenes using $\mathrm{R}_{3} \mathrm{SiBPin}$ and organic fluorides, including aryl and alkyl fluorides, via selective C-F bond activation (Zhou et al., 2021). The substrate-scope showed slightly better yields when the reaction was performed in the presence of an $\mathrm{Ni}$-catalyst, although we noticed that the effect of Ni-catalyst was not significant (Scheme 1E). While the results of Uchiyama and co-workers (Scheme 1D); (Kojima et al., 2019) and our recent results (Scheme 1E); (Zhou et al., 2021) indicate that Ni-catalyst is not necessary for their transformations, the conditions are not precisely the same such as bases, solvents and reaction times, which is difficult to conclude the Ni-effect. We thus decided to carefully re-examine our original work of defluorosilylation of aryl fluorides in 2018 (Scheme 1A); (Cui et al., 2018) by the same conditions, $\mathrm{R}_{3} \mathrm{SiBPin}$ in the presence of $\mathrm{KO} t \mathrm{Bu}$, with or without an Ni-catalyst. We disclose herein the improved-catalyst-free conditions for silylboronate-mediated defluorosilylation of aryl fluorides. A wide variety of aryl fluorides 1 having a substitution at the aromatic ring were smoothly converted into the corresponding aryl silanes $\mathbf{3}$ in good yields by $\mathrm{R}_{3} \mathrm{SiBPin} 2$ (2.0 equiv) in the presence of $\mathrm{KO} t \mathrm{Bu}$ ( 3.0 equiv) in a mixed solvent system $(c$-hex/THF $=1 / 2)$ at room temperature. 
TABLE 1 | Optimization of defluorosilylation reaction conditions.
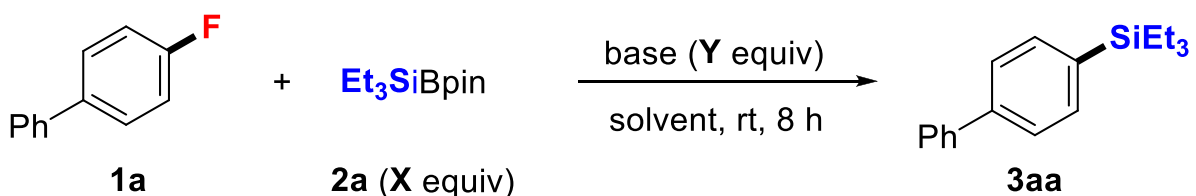

$1 \mathrm{a}$

2a (X equiv)

\begin{tabular}{ll}
\multicolumn{1}{c}{ Solvent } & Yield of 3aa $^{\mathbf{a}}$ \\
\hline c-hex/THF (1/2) & $65 \%$ \\
c-hex/THF (1/2) & $58 \%$ \\
c-hex/THF (1/2) & N.R. \\
c-hex/THF (1/2) & N.R. \\
c-hex/THF (1/2) & N.R. \\
c-hex/THF (1/2) & $27 \%$ \\
c-hex & $45 \%$ \\
THF & $62 \%$ \\
diglyme & $45 \%$ \\
c-hex/THF (1/2) & $60 \%$ \\
c-hex/THF (1/2) & $74 \%(56 \%)^{c}$ \\
c-hex/THF (1/2) & $83 \%(65 \%)^{c}$
\end{tabular}

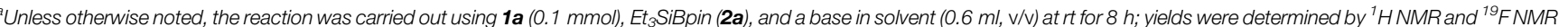
analysis of the crude reaction mixture using 3 -fluoropyridine as the internal standard.

${ }^{\mathrm{b}} 10 \mathrm{~mol} \% \mathrm{Ni}(\mathrm{Cod})_{2}$ was added.

cIsolated yield is shown in parentheses.

Heteroaromatic fluorides $\mathbf{1}$ are also accepted by the same conditions to provide heteroaromatic silanes $\mathbf{3}$ in good yields. We also carried out the same reactions under $\mathrm{Ni}$-catalysis. While the yields under the catalyst-free conditions were lower than those under Ni-catalysis, the transition-metal-free system is advantageous from the perspective of green chemistry (Scheme 1F).

\section{RESULTS AND DISCUSSION}

To start the optimization, we selected 4-fluorobiphenyl (1a) and silylboronate $\mathrm{Et}_{3} \mathrm{SiBpin}(\mathbf{2 a})$ as model substrates to examine the defluorosilylation reaction. Based on our earlier reported conditions of the Ni-catalyzed defluorinative silylation of aryl fluorides 1 [ $\mathrm{Et}_{3} \mathrm{SiBpin}$ (1.5 equiv), $\mathrm{KO} t \mathrm{Bu}$ ( 2.5 equiv), $10 \mathrm{~mol} \%$ $\mathrm{Ni}(\operatorname{cod})_{2}$ in cyclohexane $(c$-hex $) / \mathrm{THF}(1 / 2, v / v)$ at room temperature], we carried out the reaction of $\mathbf{1 a}$ with $\mathbf{2} \mathbf{a}$ under the conditions mentioned above but without Ni-catalyst. All the optimizations were carried out on a $0.1 \mathrm{mmol}$ scale of 1a. The expected biphenyl-4-yl-triethylsilane (3aa) was observed in 65\% ${ }^{1} \mathrm{H}$ NMR yield after $8 \mathrm{~h}$ (entry 1 , Table 1 ). To compare Uchiyama's reaction conditions (Kojima et al., 2019) ( $\mathrm{NaO} t \mathrm{Bu}, \mathrm{THF})$, replacing $\mathrm{KO} t \mathrm{Bu}$ with $\mathrm{NaO} t \mathrm{Bu}$, gave $58 \%$ yield of 3aa (entry 2). Other bases such as $\mathrm{LiO} t \mathrm{Bu}$ or KOMe resulted in no reaction (entries 3 and 4). The conditions by Martin (Liu et al., 2019) (LiHMDS, DME) were also attempted but using our solvent system $(c$-hex/THF $=1 / 2, v /$ $v$ ), but no reaction resulted (entry 5). Interestingly, KHMDS facilitated this defluorosilylation reaction by affording $\mathbf{3 a a}$ in $27 \%$ yield (entry 6 ). We subsequently attempted the reaction in a single solvent of $c$-hex, THF, or diglyme to investigate the effect of solvent. The mixed solvent system, $c$-hex/THF (entry 1), was more effective than others (entries 7-9). We next varied the amounts of $2 \mathbf{a}$ and $\mathrm{KO} t \mathrm{Bu}$ (entries 10 and 11 ) and found that 2.0 equiv of $\mathbf{2 a}$ and 3.0 equiv of $\mathrm{KO} t \mathrm{Bu}$ were the optimum amounts to afford $\mathbf{3 a a}$ in $74 \%$ yield (56\% isolated yield; entry 11 ). To re-ascertain the effect of $\mathrm{Ni}(\mathrm{COD})_{2}$, we investigated the reaction using these optimized conditions (entry 11) but in the presence of $\mathrm{Ni}$ catalyst. The defluorosilylation reaction performed more efficiently under the optimal conditions with $\mathrm{Ni}(\mathrm{COD})_{2}$ to give 3aa in $83 \%$ yield ( $65 \%$ isolated yield; entry 12 ), while 1a remained (detected by crude ${ }^{19} \mathrm{~F}$ NMR). These comparative results thus convinced us that $\mathrm{Ni}(\mathrm{COD})_{2}$ accelerates the present defluorinative transformation, while the transition-metal-free variant (entry 11) is advantageous from a green chemistry perspective.

With the optimized reaction conditions in hand (entry 11, Table 1), we next examined the feasibility of this transitionmetal-free defluorosilylation reaction (Table 2). All the reactions were carried out on a $0.2 \mathrm{mmol}$ scale of $\mathbf{1}$. As shown, various aromatic fluorides were examined under catalyst-free conditions. We efficiently converted a wide range of fluoroarenes $\mathbf{1}$ into corresponding defluorosilylation products $\mathbf{3}$ in good yield. It was found that any position $(o-, m-$, or $p$-) in the aromatic substitution of 1 was viable, affording the corresponding products 3 (3aa: 59\%; 3ba: 51\%; 3ca: 26\%; 3da: 40\%; 3ea: 55\%) in acceptable to good yields $(26-59 \%)$ under the catalyst-free conditions. We next repeated the same substrate scope in the presence of $\mathrm{Ni}(\mathrm{COD})_{2}$ (entry 12, Table 1) and the yield of products 3aa-3ea improved considerably (3aa: $86 \%$; 3ba: $82 \%$; 3ca: 74\%; 3da: 70\%; 3ea: 79\%). Thus, these differences clearly show the efficiency of $\mathrm{Ni}(\mathrm{COD})_{2}$. Previous results with $\mathrm{Ni}(\mathrm{COD})_{2}$ are also indicated in Table 1 to ascertain the advantage of the $\mathrm{Ni}$ catalyst. Besides, the aryl fluorides $\mathbf{1 f}-\mathbf{1 h}$ with an electron-rich substitution were well-tolerated in this defluorosilylation reaction in moderate yield (3fa: 46\%; 3ga: 45\%; 3ha: 39\%). Several substituted aryl silanes (3ia-3na) were also successfully obtained in moderate yield under identical conditions and a variety of functional groups such as OMe (1j), OMOM (1k), $\mathrm{OPh}(\mathbf{1 1}), \mathrm{NMe}_{2}(\mathbf{1 m})$ and $1 \mathrm{H}$-pyrrole (1n) were well tolerated. 
TABLE 2 | Substrate scope of the defluorosilylation strategies ${ }^{a}$.

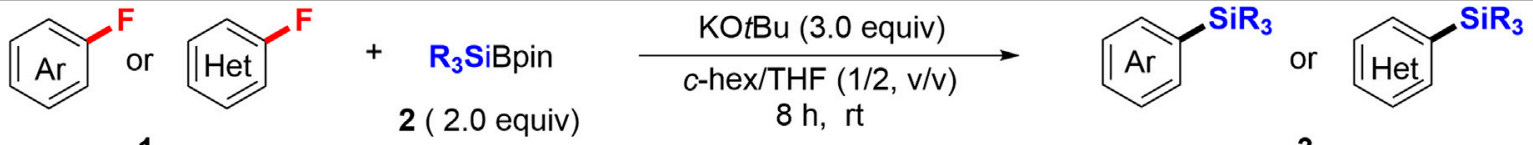

product 3, \% yield<smiles>CC[SiH](CC)c1ccc(-c2ccccc2)cc1</smiles>

3aa: $59 \%$

with [Ni]: $86 \%$ with [Ni]: $71 \%{ }^{[b]}$<smiles></smiles>

3fa: $46 \%$ with [Ni]: $84 \%{ }^{[b]}$
$\mathrm{Ph}$<smiles>CC[SiH](CC)c1cccc(C)c1</smiles>

3ba: $51 \%$ with [Ni]: $82 \%$ with [Ni]: $76 \%$ [b]<smiles>CC[SiH](CC)c1ccccc1-c1ccccc1</smiles>

3ca: $26 \%$ with [Ni]: $74 \%$ with [Ni]: 69\%[b]<smiles>CC[SiH]c1cccc2ccccc12</smiles>

3da: $40 \%$ [c]

with [Ni]: $70 \%$

with [Ni]: $61 \%{ }^{[\mathrm{b}]}$<smiles>CC[SiH](CC)c1ccc(-c2cccc3ccccc23)cc1</smiles>

3ea: $55 \%$

with [Ni]: $79 \%$<smiles>CC[SiH](CC)c1ccc(-c2ccc3c(c2)OCO3)cc1</smiles>

3ha: $39 \%$ with [Ni]: $51 \%\left[{ }^{[b]}\right.$<smiles>CC[SiH](CC)c1ccccc1</smiles>

3ia: $48 \%[c]$ with [Ni]: $75 \%{ }^{[b]}$<smiles>CC[SiH](CC)c1ccc(OC)cc1</smiles>
with [Ni]: $70 \%{ }^{[\mathrm{b}]}$ 3ja: $32 \%$ [c]<smiles>CC[SiH](CC)c1ccc(OC)cc1</smiles>

3ka: $25 \%$ with [Ni]: $58 \%\left[{ }^{[b]}\right.$<smiles>CC[SiH](CC)c1ccc(Oc2ccccc2)cc1</smiles>

3la: $41 \%$ with [Ni]: $65 \%$ [b]<smiles>CC[SiH](CC)c1ccc(N(C)C)cc1</smiles>

3ma: $41 \%$ with [Ni]: $77 \%{ }^{[\mathrm{b}]}$<smiles>CC[SiH](C)c1ccc(-n2cccc2)cc1</smiles>

3na: $46 \%$ with [Ni]: $62 \%{ }^{[\mathrm{b}]}$<smiles>CC[SiH](CC)c1ccc(-c2ccccc2)nc1</smiles>

3oa: $43 \%$ with [Ni]: $76 \%$<smiles>CC[SiH]c1ccc2ccn(C)c2c1</smiles><smiles>CC[SiH](CC)c1ccc(-c2cc3ccccc3n2C)cc1</smiles>

3pa: $37 \%$ with [Ni]: $71 \%{ }^{[b]}$<smiles>c1ccc([SiH2]c2ccc(-c3ccccc3)cc2)cc1</smiles>

3ab: $36 \%$ with [Ni]: $55 \%[$ [b]<smiles>CC[SiH](CC)c1ccccc1F</smiles>

3ra: $62 \%[\mathrm{c}]$ with [Ni]: $70 \%{ }^{[\mathrm{b}]}$<smiles>CC[SiH](CC)c1ccccc1OC</smiles>

3sa: $26 \%$ [c] with [Ni]: $67 \%$<smiles>CCc1ccccc1CC</smiles>

3ta: $12 \%$ [c]

with [Ni]: $35 \%$
Unsuccessful Substrates:<smiles>O=C(c1ccccc1)c1ccc(F)cc1</smiles><smiles>COC(=O)c1cc(F)ccc1C</smiles>

aUnless otherwise noted, the reaction was carried using 1 (0.2 mmol), 2 (2.0 equiv), and KOtBu (3.0 equiv) without or with Ni(COD) 2 (10 mol\%) in c-hex/THF (1.2 ml, 1/2, v/v) at rt for 8 h. Isolated yields are shown.

${ }^{b}$ The yields shown are previously reported data by using reaction conditions: 1 (0.2 mmol), 2 (1.5 equiv), Ni(COD) 2 (10 mol\%), KOtBu (2.5 equiv), c-hex/THF (0.8 ml, 1/2, v/v), rt, 2-12 h.

${ }^{\circ} 0.4 \mathrm{mmol} 1$ was used.

PMP, p-methoxyphenyl; MOM, methoxymethyl. 


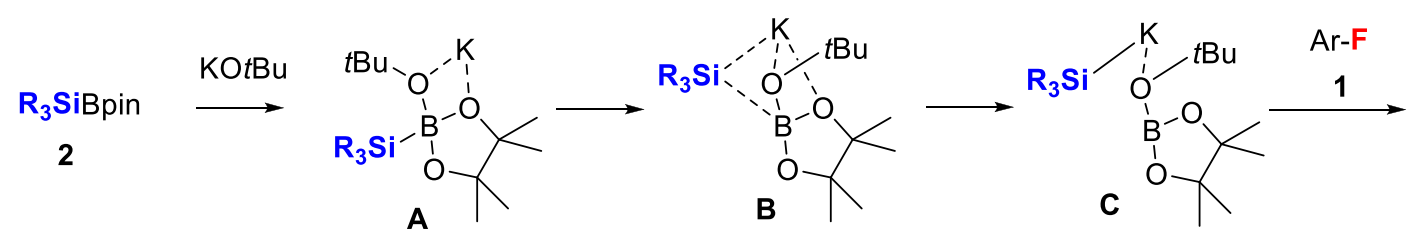

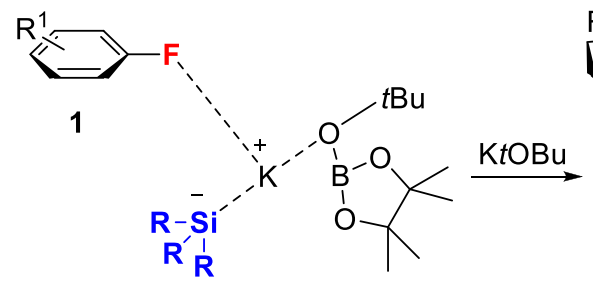

I

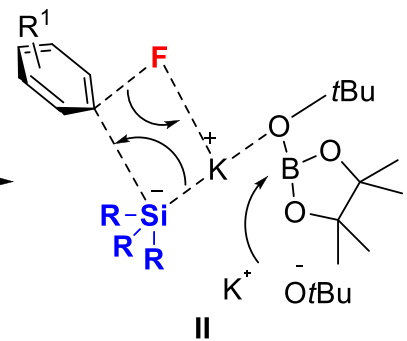

II

SCHEME 2 | A schematic of the reaction process of catalyst-free defluorosilylation of aryl fluorides $\mathbf{1}$ with $\mathrm{R}_{3}$ SiBPin $\mathbf{2}$ in the presence of $t$ BuOK.

The nitrogen-containing hetero-aromatic fluorides 1o-1q were successfully converted to the corresponding silanes 3 . For example, 5-fluoro-2-phenylpyridine (10) and $1 \mathrm{H}$-indole derivatives (1p and 1q), which possess an active $\mathrm{C}-\mathrm{H}$ bond, were well-tolerated and smoothly underwent the selective defluorosilylation process to afford desired products (3oa: 43\%; 3pa: 37\%; 3qa: 42\%). Notably, 1,2-difluorobenzene (1r) was efficiently mono-silylated in good yield (3ra: 62\%). Sterically demanding $o$-substituted substrates 1 s and $\mathbf{1 t}$ were also transformed into the corresponding products $3 \mathbf{s a}$ and $\mathbf{3 t a}$ under $\mathrm{Ni}$-free conditions in 26 and $12 \%$ yields, respectively. Ni-catalyst conditions improved both cases to 67\% (3sa) and $35 \%$ (3ta). Furthermore, other silyl boronates such as $\mathrm{PhMe}_{2} \mathrm{SiBpin}$ (2b) and $t \mathrm{BuMe}_{2} \mathrm{SiBPin}$ (2c) were also investigated instead of $\mathbf{2 a}$ to yield the corresponding silylated products $\mathbf{3 a b}$ and $\mathbf{3 a c}$ in 36 and 51\% yield, respectively. In all cases, the Ni catalyst-based protocol (Cui et al., 2018) has a substantial yield advantage in this defluorosilylation reaction, while both conditions did not entirely consume the staring materials 1. The substrates (1u and 1v) having electronwithdrawing group were not suitable, which is the limitation of this transformation.

Based on our previous work of defluorosilylation of alkyl fluorides 1 with $\mathrm{R}_{3} \mathrm{SiBPin} \mathbf{2}$ mediated by a potassium base (Cui et al., 2018), the defluorosilylation of aryl fluorides mediated by a lithium base (Martin) (Liu et al., 2019) and by a sodium base (Uchiyama) (Kojima et al., 2019), the reaction should proceed the nucleophilic attack of the silyl anion involving a concerted $S_{N} A r$ process. A schematic reaction of the catalyst-free defluorosilylation process is presented in Scheme $\mathbf{2}$ by considering our previous work and Uchiyama's elegant DFT calculations (Kojima et al., 2019). First, $\mathrm{R}_{3} \mathrm{SiBPin} 2$ reacts with $t \mathrm{BuOK}$ to provide potassium silyl anion species $\mathbf{C}$ complexed with $t \mathrm{BuO}-\mathrm{BPin}$ via $\mathbf{A}$ and $\mathbf{B}$ (Cui et al., 2018; Jain et al., 2018; Zhou et al., 2021). C approaches the aryl fluoride 1 to form the intermediate $\mathrm{I}$. A concerted $\mathrm{S}_{\mathrm{N}} \mathrm{Ar}$ reaction happens with the attack of the boron center of $t \mathrm{BuO}$-BPin by another $t \mathrm{BuOK}$ via a transition state II with the key C-F bond cleavage to furnish the aryl silanes 3 with the formation of $\mathrm{KF}$ and $\mathrm{D}, \mathrm{K}^{+}\left[t \mathrm{BuO}_{2} \mathrm{BPin}\right]-$.

\section{CONCLUSION}

In summary, we reported a feasible transition-metal-free method for synthesizing aryl silanes 3 through the defluorosilylation of aryl fluorides $\mathbf{1}$ by using silylboronates $\mathrm{R}_{3} \mathrm{SiBPin} 2$ and $\mathrm{KO} t \mathrm{Bu}$. Furthermore, we compared our new results with a previous report on the success of $\mathrm{Ni}$ catalyzed defluorosilylation of fluoroarenes. Thus, we concluded that the transformation of aryl fluorides into corresponding aryl silanes via a $\mathrm{C}-\mathrm{F}$ bond cleavage can be achieved even in the absence of $\mathrm{Ni}(\mathrm{COD})_{2}$, but in relatively lower yields than those of the $\mathrm{Ni}$-catalyzed protocol, due to different reaction mechanisms. A further extension of this methodology is currently underway.

\section{DATA AVAILABILITY STATEMENT}

The original contributions presented in the study are included in the article/Supplementary Material, further inquiries can be directed to the corresponding author.

\section{AUTHOR CONTRIBUTIONS}

NS conceived the concept. JZ and ZZ optimized the reaction conditions and surveyed the substrate scope. NS directed the project. NS and JZ prepared the manuscript.

\section{FUNDING}

This work was supported by JSPS KAKENHI grant $21 \mathrm{H} 01933$ (KIBAN B, NS).

\section{SUPPLEMENTARY MATERIAL}

The Supplementary Material for this article can be found online at: https://www.frontiersin.org/articles/10.3389/fchem.2021.771473/ full\#supplementary-material 


\section{REFERENCES}

Ahrens, T., Kohlmann, J., Ahrens, M., and Braun, T. (2015). Functionalization of Fluorinated Molecules by Transition-Metal-Mediated C-F Bond Activation to Access Fluorinated Building Blocks. Chem. Rev. 115, 931-972. doi:10.1021/ cr500257c

Alonso, C., Martínez de Marigorta, E., Rubiales, G., and Palacios, F. (2015). Carbon Trifluoromethylation Reactions of Hydrocarbon Derivatives and Heteroarenes. Chem. Rev. 115, 1847-1935. doi:10.1021/cr500368h

Améduri, B. (2020). The Promising Future of Fluoropolymers. Macromol. Chem. Phys. 221, 1900573-1900586. doi:10.1002/macp.201900573

Amii, H., and Uneyama, K. (2009). C-F Bond Activation in Organic Synthesis. Chem. Rev. 109, 2119-2183. doi:10.1021/cr800388c

Babudri, F., Farinola, G. M., Naso, F., and Ragni, R. (2007). Fluorinated Organic Materials for Electronic and Optoelectronic Applications: the Role of the Fluorine Atom. Chem. Commun. 43, 1003-1022. doi:10.1039/B611336B

Berger, R., Resnati, G., Metrangolo, P., Weber, E., and Hulliger, J. (2011). Organic Fluorine Compounds: a Great Opportunity for Enhanced Materials Properties. Chem. Soc. Rev. 40, 3496-3508. doi:10.1039/C0CS00221F

Campbell, M. G., and Ritter, T. (2015). Modern Carbon-Fluorine Bond Forming Reactions for Aryl Fluoride Synthesis. Chem. Rev. 115, 612-633. doi:10.1021/ cr500366b

Charpentier, J., Früh, N., and Togni, A. (2015). Electrophilic Trifluoromethylation by Use of Hypervalent Iodine Reagents. Chem. Rev. 115, 650-682. doi:10.1021/ cr500223h

Chen, H., Reinhard, M., Yin, T., Nguyen, T. V., Tran, N. H., and Yew-Hoong Gin, K. (2019). Multi-compartment Distribution of Perfluoroalkyl and Polyfluoroalkyl Substances (PFASs) in an Urban Catchment System. Water Res. 154, 227-237. doi:10.1016/j.watres.2019.02.009

Coates, G., Tan, H. Y., Kalff, C., White, A. J. P., and Crimmin, M. R. (2019). Defluorosilylation of Industrially Relevant Fluoroolefins Using Nucleophilic Silicon Reagents. Angew. Chem. Int. Ed. 58, 12514-12518. doi:10.1002/ anie. 201906825

Cui, B., Jia, S., TokunagaShibata, E. N., and Shibata, N. (2018). Defluorosilylation of Fluoroarenes and Fluoroalkanes. Nat. Commun. 9, 4393. doi:10.1038/s41467018-06830-w

Eisenstein, O., Milani, J., and Perutz, R. N. (2017). Selectivity of C-H Activation and Competition between C-H and C-F Bond Activation at Fluorocarbons. Chem. Rev. 117, 8710-8753. doi:10.1021/acs.chemrev.7b00163

Furuya, T., Kamlet, A. S., and Ritter, T. (2011). Catalysis for Fluorination and Trifluoromethylation. Nature 473, 470-477. doi:10.1038/nature10108

Gao, P., Wang, G., Xi, L., Wang, M., Li, S., and Shi, Z. (2019). Transition-MetalFree Defluorosilylation of Fluoroalkenes with Silylboronates. Chin. J. Chem. 37, 1009-1014. doi:10.1002/cjoc.201900310

Hamel, J.-D., and Paquin, J.-F. (2018). Activation of C-F Bonds a to C-C Multiple Bonds. Chem. Commun. 54, 10224-10239. doi:10.1039/C8CC05108A

Hiyama, T. (2000). "Biologically Active Organofluorine Compounds," in Organofluorine Compounds. Editor H. Yamamoto (Springer-verlag Berlin Heidelberg), 137-182. doi:10.1007/978-3-662-04164-2_5

Inoue, M., Sumii, Y., and Shibata, N. (2020). Contribution of Organofluorine Compounds to Pharmaceuticals. ACS Omega 5, 10633-10640. doi:10.1021/ acsomega.0c00830

Jain, P., Pal, S., and Avasare, V. (2018). Ni(COD)2-Catalyzed Ipso-Silylation of 2Methoxynaphthalene: A Density Functional Theory Study. Organometallics 37, 1141-1149. doi:10.1021/acs.organomet.8b00046

Kojima, K., Nagashima, Y., Wang, C., and Uchiyama, M. (2019). In SituGeneration of Silyl Anion Species through Si-B Bond Activation for the Concerted Nucleophilic Aromatic Substitution of Fluoroarenes. ChemPlusChem 84, 277-280. doi:10.1002/cplu.201900069

Lee, J.-W., Oliveira, M. T., Jang, H. B., Lee, S., Chi, D. Y., Kim, D. W., et al. (2016). Hydrogen-bond Promoted Nucleophilic Fluorination: Concept, Mechanism and Applications in Positron Emission Tomography. Chem. Soc. Rev. 45, 4638-4650. doi:10.1039/C6CS00286B

Li, P., Oyang, X., Xie, X., Guo, Y., Li, Z., Xi, J., et al. (2020). Perfluorooctanoic Acid and Perfluorooctane Sulfonate Co-exposure Induced Changes of Metabolites and Defense Pathways in Lettuce Leaves. Environ. Pollut. 256, 113512. doi:10.1016/j.envpol.2019.113512
Lim, S., Cho, H., Jeong, J., Jang, M., Kim, H., Cho, S. H., et al. (2020). Cobaltcatalyzed Defluorosilylation of Aryl Fluorides via Grignard Reagent Formation. Org. Lett. 22, 7387-7392. doi:10.1021/acs.orglett.0c02752

Liu, X., Xu, C., Wang, M., and Liu, Q. (2015). Trifluoromethyltrimethylsilane: Nucleophilic Trifluoromethylation and beyond. Chem. Rev. 115, 683-730. doi: $10.1021 / \mathrm{cr} 400473 \mathrm{a}$

Liu, Q., Ni, C., and Hu, J. (2017). China's Flourishing Synthetic Organofluorine Chemistry: Innovations in the New Millennium. Natl. Sci. Rev. 4, 303-325. doi:10.1093/nsr/nwx058

Liu, X.-W., Zarate, C., and Martin, R. (2019). Base-Mediated Defluorosilylation of $\mathrm{C}(\mathrm{sp} 2)-\mathrm{F}$ and $\mathrm{C}(\mathrm{sp} 3$ )-F Bonds. Angew. Chem. Int. Ed. 58, 2064-2068. doi:10.1002/anie.201813294

Liu, Y., Jiang, L., Wang, H., Wang, H., Jiao, W., Chen, G., et al. (2019). A Brief Review for Fluorinated Carbon: Synthesis, Properties and Applications. Nanotechnol. Rev. 8, 573-586. doi:10.1515/ntrev-2019-0051

Luo, Y.-R. (2007). "BDEs of C-Halogen Bonds," in Comprehensive Handbook of Chemical Bond Energies. Y.-R. Luo, (ed) 1st ed. (Boca Raton, FL: CRC Press), 211-253. doi:10.1201/9781420007282-5

Ma, J.-A., and Cahard, D. (2004). Asymmetric Fluorination, Trifluoromethylation, and Perfluoroalkylation Reactions. Chem. Rev. 104, 6119-6146. doi:10.1021/ cr030143e

Mallick, S., Xu, P., Würthwein, E.-U., and Studer, A. (2019). Silyldefluorination of Fluoroarenes by Concerted Nucleophilic Aromatic Substitution. Angew. Chem. Int. Ed. 58, 283-287. doi:10.1002/anie.201808646

McCulloch, A. (2003) Fluorocarbons in the Global Environment: a Review of the Important Interactions with Atmospheric Chemistry and Physics. Sciencej. Fluor. Chem. 315123, 180421-180529. doi:10.1016/S0022-1139(03)00105-2

Merino, E., and Nevado, C. (2014). Addition of CF3 across Unsaturated Moieties: a Powerful Functionalization Tool. Chem. Soc. Rev. 43, 6598-6608. doi:10.1039/ C4CS00025K

Ni, C., Hu, M., and Hu, J. (2015). Good Partnership between Sulfur and Fluorine: Sulfur-Based Fluorination and Fluoroalkylation Reagents for Organic Synthesis. Chem. Rev. 115, 765-825. doi:10.1021/cr5002386

Ogawa, Y., Tokunaga, E., Kobayashi, O., Hirai, K., and Shibata, N. (2020). Current Contributions of Organofluorine Compounds to the Agrochemical Industry. iScience 23, 101467-110519. doi:10.1016/j.isci.2020.101467

Shibata, N., Ishimaru, T., Nakamura, S., and Toru, T. (2007). New Approaches to Enantioselective Fluorination: Cinchona Alkaloids Combinations and Chiral Ligands/metal Complexes. J. Fluorine Chem. 128, 469-483. doi:10.1016/ j.jfluchem.2006.12.014

Sheldon, D. J., CoatesCrimmin, G. M. R., and Crimmin, M. R. (2020). Defluorosilylation of Trifluoromethane: Upgrading an Environmentally Damaging Fluorocarbon. Chem. Commun. 56, 12929-12932. doi:10.1039/ D0CC04592F

Shen, Q., Huang, Y.-G., Liu, C., Xiao, J.-C., Chen, Q.-Y., and Guo, Y. (2015). Review of Recent Advances in CF Bond Activation of Aliphatic Fluorides. J. Fluorine Chem. 179, 14-22. doi:10.1016/j.jfluchem.2015.07.007

Shibata, N., Ishimaru, T., Nakamura, S., and Toru, T. (2007). New Approaches to Enantioselective Fluorination: Cinchona Alkaloids Combinations and Chiral Ligands/metal Complexes. J. Fluorine Chem. 128, 469-483. doi:10.1016/ j.jfluchem.2006.12.014

Shibata, N., Mizuta, S., and Kawai, H. (2008). Recent Advances in Enantioselective Trifluoromethylation Reactions. Tetrahedron: Asymmetry 19, 2633-2644. doi:10.1016/j.tetasy.2008.11.011

Shibata, N., Matsnev, A., and Cahard, D. (2010). Shelf-stable Electrophilic Trifluoromethylating Reagents: a Brief Historical Perspective. Beilstein J. Org. Chem. 6. doi:10.3762/bjoc.6.65

Shine, K. P., and Sturges, W. T. (2007). CO2 is Not the only gas. Science 315 1804-1805. doi:10.1126/science.1141677

Sovacool, B. K., Griffiths, S., Kim, J., and Bazilian, M. (2021). Climate Change and Industrial F-Gases: a Critical and Systematic Review of Developments, Sociotechnical Systems and Policy Options for Reducing Synthetic Greenhouse Gas Emissions. Renew. Sustain. Energ. Rev. 141, 110759-110813. doi:10.1016/j.rser.2021.110759

Stahl, T., Klare, H. F. T., and Oestreich, M. (2013). Main-Group Lewis Acids for C-F Bond Activation. ACS Catal. 3, 1578-1587. doi:10.1021/cs4003244

Stanifer, J. W., Stapleton, H. M., Souma, T., Wittmer, A., Zhao, X., and Boulware, L. E. (2018). Perfluorinated Chemicals as Emerging Environmental Threats to Kidney Health. Cjasn 13, 1479-1492. doi:10.2215/CJN.04670418 
Uneyama, K. (2006). Organofluorine Chemistry. Blackwell: Wiley.

Velders, G. J. M., Andersen, S. O., Daniel, J. S., Fahey, D. W., and Mcfarland, M. (2007). The Importance of the Montreal Protocol in Protecting Climate. Proc. Natl. Acad. Sci. 104, 4814-4819. doi:10.1073/pnas.0610328104

Vierke, L., Staude, C., Biegel-Engler, A., Drost, W., and Schulte, C. (2012). Perfluorooctanoic Acid (PFOA) - Main Concerns and Regulatory Developments in Europe from an Environmental point of View. Environ. Sci. Eur. 24, 16-26. doi:10.1186/2190-4715-24-16

Xiao, H., Zhang, Z., Fang, Y., Zhu, L., and Li, C. (2021). Radical Trifluoromethylation. Chem. Soc. Rev. 50, 6308-6319. doi:10.1039/ D1CS00200G

Zhou, J., Jiang, B., Fujihira, Y., Zhao, Z., Imai, T., and Shibata, N. (2021). Catalystfree Carbosilylation of Alkenes Using Silyl Boronates and Organic Fluorides via Selective C-F Bond Activation. Nat. Commun. 12, 3749. doi:10.1038/s41467021-24031-w

Zhu, Y., Han, J., Wang, J., Shibata, N., Sodeoka, M., Soloshonok, V. A., et al. (2018). Modern Approaches for Asymmetric Construction of Carbon-Fluorine Quaternary Stereogenic Centers: Synthetic Challenges and Pharmaceutical Needs. Chem. Rev. 118, 3887-3964. doi:10.1021/acs.chemrev.7b00778
Conflict of Interest: The authors declare that the research was conducted in the absence of any commercial or financial relationships that could be construed as a potential conflict of interest.

The reviewer SF declared a past co-authorship with one of the authors NS to the handling Editor.

Publisher's Note: All claims expressed in this article are solely those of the authors and do not necessarily represent those of their affiliated organizations, or those of the publisher, the editors and the reviewers. Any product that may be evaluated in this article, orclaim that may be made by its manufacturer, is not guaranteed or endorsed by the publisher.

Copyright $\odot 2021$ Zhou, Zhao and Shibata. This is an open-access article distributed under the terms of the Creative Commons Attribution License (CC BY). The use, distribution or reproduction in other forums is permitted, provided the original author(s) and the copyright owner(s) are credited and that the original publication in this journal is cited, in accordance with accepted academic practice. No use, distribution or reproduction is permitted which does not comply with these terms. 